\title{
The Prevalence of, Hypertension and Diabetes in Ogugu, Ogbagebe and Ofabo, Ofu and Olamaboro Lga, Kogi State, Nigeria: A Report
}

Aisha Ojone Abu*

New African Chapter, Ahmadu Bello University, Nigeria

\begin{abstract}
Urinalysis, Malaria Parasite test, blood pressure checks and body mass index was calculated for the people of Ogugu, Ogbegebe and Ofabo Communities, diagnoses made and drugs administered. 356 Persons benefited from this scheme out of which $25(7.02 \%)$ were children and $331(92.97 \%)$ adults. 95 suffered from high blood pressure (26.69\%) with the highest being $250 / 120 \mathrm{mmhg}, 11$ were diabetic (3.09\%).
\end{abstract}

Keywords: Hypertension; The economic transition; Blood pressure; Cardiovascular disease; Diabetes

\section{Introduction}

The prevalence of hypertension is an important risk factor for cardiovascular disease (CVD) is increasing in the developing countries and this may be connected with the economic transition in those countries [1]. High blood pressure causes one in every eight deaths worldwide [2]. About one billion adults, the world over, had hypertension in the year 2000, and the number is expected to rise to 1.56 billion in 2015 [3]. According to a report to show the blood pressure pattern in Kogi State, it was observed that there was a high prevalence rate of hypertension amongst adults, hence, there is an urgent need to address the issue, this is why the BP screening was conducted to identify cases and treat accordingly [1-3].

Urinalysis, malaria test, blood pressure checks was conducted to reveal cases of malaria, high blood pressure, diabetes and treat them accordingly to reduce their prevalence in the afore-mentioned communities. Ogugu Community has a population of 180,000 according to the 2006 census. Below is the population of Kogi State according to each Local Government Area (Table 1).

\section{Methodology}

A total of 356 persons from 3 places of domicile were studied. Rapid diagnostic test kit was used to test for malaria (Figure 1). Urine dipsticks used for urinalysis. Manual and electronic BP apparatus used to check blood pressure. Beneficiaries moved from the Microbiological bench

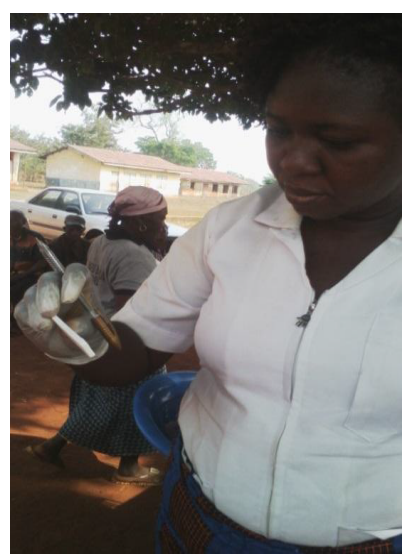

Figure 1: Diagnostic test kit was used to test for malaria. to the doctor's bench for diagnoses. Children were dewormed with Albendazole, cases of malaria, high blood pressure and diabetes were treated with ACT, Anti-hypertensive and Glucophage respectively.

\section{Result}

356 Persons benefited from this scheme out of which 25 (7.02\%)

\begin{tabular}{|l|c|c|c|c|}
\hline \multirow{2}{*}{ Name } & Status & Population & Population & Population \\
\cline { 3 - 5 } & & Census & Census & Projection \\
\cline { 3 - 5 } & & $\mathbf{2 6 - 1 1 - 1 9 9 1}$ & $\mathbf{2 1 - 0 3 - 2 0 0 6}$ & $\mathbf{2 1 - 0 3 - 2 0 1 1}$ \\
\hline Kogi & State & $21,47,756$ & $33,14,043$ & $38,50,400$ \\
\hline Adavi & Local Government Area & $1,57,092$ & $2,17,219$ & $2,52,370$ \\
\hline Ajaokuta & Local Government Area & 97,904 & $1,22,432$ & $1,42,250$ \\
\hline Baspa & Local Government Area & $\ldots$ & $2,66,176$ & $3,09,250$ \\
\hline Dekina & Local Government Area & 88,496 & $1,39,687$ & $1,62,290$ \\
\hline Ibaji & Local Government Area & $1,77,513$ & $2,60,968$ & $3,03,200$ \\
\hline Idah & Local Government Area & $\ldots$ & $1,27,572$ & $1,48,220$ \\
\hline Igalamela-Odolu & Local Government Area & $\ldots$ & 79,755 & 92,660 \\
\hline ljumu & Local Government Area & $\ldots$ & $1,47,048$ & $1,70,850$ \\
\hline Kabba/Bunu & Local Government Area & 66,603 & $1,18,593$ & $1,37,790$ \\
\hline Kogi & Local Government Area & $\ldots$ & $1,44,579$ & $1,67,980$ \\
\hline Lokoja & Local Government Area & 82,483 & $1,15,100$ & $1,33,730$ \\
\hline Mopa-Muro & Local Government Area & $\ldots$ & $1,96,643$ & $2,28,470$ \\
\hline Ofu & Local Government Area & $\ldots$ & 43,760 & 50,840 \\
\hline Ogori/Magongo & Local Government Area & $1,08,095$ & $1,91,480$ & $2,22,470$ \\
\hline Okehi & Local Government Area & $\ldots$ & 39,807 & 46,250 \\
\hline Okene & Local Government Area & $1,46,264$ & $2,23,574$ & $2,59,760$ \\
\hline Olamaboro & Local Government Area & $\ldots$ & $3,25,623$ & $3,78,320$ \\
\hline Omala & Local Government Area & $1,04,705$ & $1,58,490$ & $1,84,140$ \\
\hline Yagba East & Local Government Area & $\ldots$ & $1,07,968$ & $1,25,440$ \\
\hline Yagba West & Local Government Area & 88,780 & $1,47,641$ & $1,71,530$ \\
\hline Nigeria & Local Government Area & 76,936 & $1,39,928$ & $1,62,570$ \\
\hline & Federal Republic & $\mathbf{8 , 8 9 , 9 2 , 2 2 0}$ & $\mathbf{1 4 0 , 4 3 1 , 7 9 0}$ & $\mathbf{1 6 4 , 7 2 8 , 6 0 0}$ \\
\hline & & & & \\
\hline
\end{tabular}

Table 1: The population of kogi state according to each local government area.

${ }^{*}$ Corresponding author: Aisha Ojone Abu, Country Director, New African Chapter Ahmadu Bello University, Tel: 2348071299200; E-mail: aishaojabu4@gmail.com

Received March 24, 2017; Accepted May 24, 2017; Published May 29, 2017

Citation: Abu AO (2017) The Prevalence of, Hypertension and Diabetes in Ogugu, Ogbagebe and Ofabo, Ofu and Olamaboro Lga, Kogi State, Nigeria: A Report. J Vasc Med Surg 5: 313. doi: 10.4172/2329-6925.1000313

Copyright: @ 2017 Abu AO. This is an open-access article distributed under the terms of the Creative Commons Attribution License, which permits unrestricted use, distribution, and reproduction in any medium, provided the original author and source are credited. 
Citation: Abu AO (2017) The Prevalence of, Hypertension and Diabetes in Ogugu, Ogbagebe and Ofabo, Ofu and Olamaboro Lga, Kogi State, Nigeria: A Report. J Vasc Med Surg 5: 313. doi: 10.4172/2329-6925.1000313

Page 2 of 2

were children and 331 (92.97\%) adults. 95 suffered from high blood pressure (26.69\%) with the highest being $250 / 120 \mathrm{mmhg}$, 11 were diabetic (3.09\%). 43 (12.07) had malaria.118 Persons benefited in Ogugu Community out of which 38 are hypertensive, 3 diabetic and 15 had malaria. 98 Persons benefited in Ogbadebe Community out of which 22 had high blood pressure, 2 diabetic and 9 had malaria. 140 Persons benefited in Ofabo Community out of which 35 were hypertension , 6 diabetic and 7 had malaria (Figures 2 and 3; Table 2).

\section{Conclusion}

It was observed that the reason for the low prevalence of malaria is due to the fact that there are little Mosquitoes this time of the year. There was a high prevalence of high blood pressure which is related to the hardship in the State.

\begin{tabular}{|c|c|c|c|c|c|}
\hline $\mathbf{S} / \mathbf{N}$ & Community & Disease/Infection & $\begin{array}{c}\text { Total } \\
\text { beneficiary }\end{array}$ & $\begin{array}{l}\text { Number of } \\
\text { Persons } \\
\text { diagnosed }\end{array}$ & $\begin{array}{l}\text { Prevalence } \\
\text { rate }\end{array}$ \\
\hline \multirow[t]{3}{*}{1} & \multirow[t]{3}{*}{ Ogugu } & Hypertension & 118 & 38 & $7358484 e+36$ \\
\hline & & Malaria & 118 & 3 & 4716.981 \\
\hline & & Diabetes & 118 & 15 & 56603.774 \\
\hline \multirow[t]{3}{*}{2} & \multirow[t]{3}{*}{ Ogbadebe } & Hypertension & 98 & 22 & $8343949 e+52$ \\
\hline & & Malaria & 98 & 2 & 38216.561 \\
\hline & & Diabetes & 98 & 9 & 254.77 \\
\hline \multirow[t]{3}{*}{3} & \multirow[t]{3}{*}{ Ofabo } & Hypertension & 140 & 35 & 09090909100 \\
\hline & & Malaria & 140 & 6 & 4.545 \\
\hline & & Diabetes & 140 & 7 & 0 \\
\hline
\end{tabular}

Table 2: A table to show the prevalence of diseases in Ogbonicha, Aloma, Ogbulu and lboko communies.

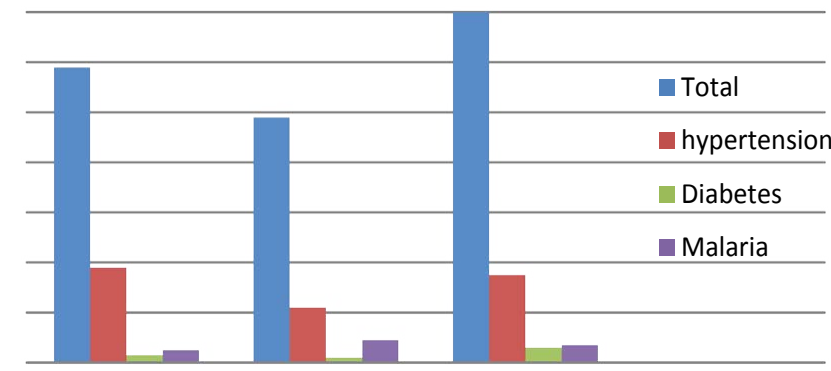

Figure 2: A graphical presentation of the prevalence of diseases in Ogbonicha Aloma, Ogbulu and Iboko communities.

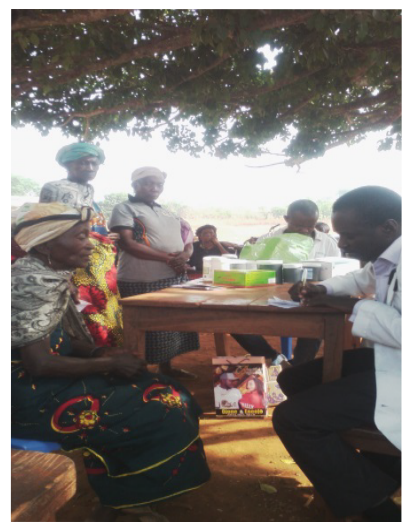

Figure 3: Provide medical care.

It is important to provide medical care, or deploy medical personnel to the communities to checkmate the spread of preventable diseases to improve the general wellbeing of the people.

\section{References}

1. Ejike CE, Ugwu CE, Ezeanyika LUS, Olayemi AT (2008) Blood pressure patterns in relation to geographic area of residence: A cross-sectional study of adolescents in Kogi state, Nigeria. BMC Public Health. 8: 411-421.

2. World Health Organization (2002) The World Health Report 2002; Reducing risk, promoting healthy. Geneva, Switzerland.

3. Kearney PM, Whelton M, Reynolds K, Muntner P, Whelton PK, et al. (2005) Global burden of hypertension: analysis of worldwide data. Lancet 365: 217-223. 